Revista Eletrônica em Gestão, Educação e Tecnologia Ambiental

REGET/UFSM (e-ISSN: 2236-1170).

\title{
EDUCAÇÃO AMBIENTAL NA ESCOLA PÚBLICA: O CASO DA E. E. E. F. JOSÉ FERREIRA RAMOS - GAURAMA/RS
}

\author{
Vanessa Aline Peretti
}

\section{RESUMO}

A relação entre meio ambiente e educação para a cidadania assume um papel cada vez mais desafiador, demandando a emergência de novos saberes para apreender processos sociais que se complexificam e riscos ambientais que se intensificam.

O objetivo da referente pesquisa foi motivar e sensibilizar as pessoas para transformar as diversas formas de participação na defesa da qualidade de vida. Destacando a educação ambiental como uma função transformadora na qual a co-responsabilização dos indivíduos tornase um objetivo essencial para modificar um quadro de crescente degradação socioambiental.

A pesquisa de campo foi realizada através de um questionário com questões referentes ao trabalho de educação ambiental em sala de aula para os professores, alunos de 1a a 4a série do ensino fundamental e funcionários da escola em estudo.

Quando indagados sobre a melhor forma de se divulgar um programa de Educação Ambiental a maioria dos entrevistados afirmou que é por meio da televisão e do rádio por serem os meios de comunicação que as famílias tem mais acesso, assistem e ouvem com frequência.

Através desta entrevista se pode concluir que quando um projeto de educação ambiental é bem elaborado, o resultado, será sem dúvida, satisfatório e trará uma mudança de hábitos e atitudes permanentes.

\section{INTRODUÇÃO}

A relação entre meio ambiente e educação para a cidadania assume um papel cada vez mais desafiador, demandando a emergência de novos saberes para apreender processos sociais que se complexificam e riscos ambientais que se intensificam.

As políticas ambientais e os programas educativos relacionados à conscientização da crise ambiental demandam cada vez mais novos enfoques integradores de uma realidade contraditória e geradora de desigualdades, que transcendem mera aplicação dos conhecimentos científicos e tecnológicos disponíveis.

O desafio é, pois, o de formular uma educação ambiental que seja crítica e inovadora, em dois níveis: formal e não formal. Assim a educação ambiental deve ser acima de tudo um ato político voltado para a transformação social. O seu enfoque deve buscar uma perspectiva de ação, que relaciona o homem, a natureza e o universo, tendo em conta que os recursos naturais se esgotam e que o principal responsável pela sua degradação é o homem.

Os grandes desafios para os educadores ambientais são, de um lado, o resgate e o desenvolvimento de valores e comportamentos (confiança, respeito, responsabilidade, compromisso, solidariedade e iniciativa) e de outro, o estímulo a uma visão global e crítica das 


\section{Revista Eletrônica em Gestão, Educação e Tecnologia Ambiental REGET/UFSM (e-ISSN: 2236-1170).}

questões ambientais e a promoção de um enfoque interdisciplinar que resgate e construa saberes.

O principal eixo de atuação da educação ambiental deve buscar, acima de tudo, a solidariedade, a igualdade e o respeito à diferença através de formas democráticas de atuação baseadas em práticas interativas e dialógicas. Isto trás o objetivo de criar novas atitudes e comportamentos diante do consumo na nossa sociedade e de estimular a mudança de valores individuais e coletivos.

Portanto, utilizando como referencial a Escola Estadual de Ensino Fundamental José Ferreira Ramos, localizada no município de Gaurama/RS, na qual representa a possibilidade de lidar com conexões entre diferentes dimensões humanas, propiciando, entrelaçamentos e múltiplos saberes. A escola participa então dessa rede, como uma instituição dinâmica com capacidade de compreender e articular os processos cognitivos com os contextos da vida.

A educação ambiental na escola ou fora dela continuará a ser uma concepção radical de educação, não porque prefere ser a tendência rebelde do pensamento educacional contemporâneo, mas sim porque nossa época e nossa herança histórica e ecológica exigem alternativas radicais, justas e pacíficas.

Atualmente, o avanço para uma sociedade sustentável é permeado de obstáculos, na medida em que existe uma restrita consciência na sociedade a respeito das implicações do modelo de desenvolvimento em curso. Pode-se afirmar que as causas básicas que provocam atividades ecologicamente predatórias são atribuídas as instituições sociais, aos sistemas de informação e comunicação e aos valores adotados pela sociedade. Isso implica principalmente a necessidade de estimular uma participação mais ativa da sociedade no debate dos seus destinos, como uma forma de estabelecer um conjunto identificado de problemas, objetivos e soluções.

O caminho a ser desenhado passa necessariamente por uma mudança no acesso á informação e por transformações institucionais que garantam acessibilidade e transparência na gestão. Existe um desafio essencial a ser enfrentado e este está centrado na possibilidade de que os sistemas de informações e as instituições sociais se tornem facilitadores de um processo que reforce os argumentos para a construção de uma sociedade sustentável. Para tanto é preciso que se criem todas as condições para facilitar o processo, suprindo dados e tornando transparentes os procedimentos por meio de práticas concentradas na educação ambiental que garantam os meios de criar novos estilos de vida e promovam uma consciência ética que questione o atual modelo de desenvolvimento, marcado pelo caráter predatório e pelo reforço das desigualdades socioambientais.

Nesse contexto a educação ambiental aponta para propostas pedagógicas centradas na conscientização, mudança de comportamento, desenvolvimento de competências, capacidade de avaliação e participação dos educandos. A educação ambiental propicia o aumento de conhecimentos, mudanças de valores e aperfeiçoamento de habilidades, condições básicas para estimular maior integração e harmonia dos indivíduos com o meio ambiente. 


\section{Revista Eletrônica em Gestão, Educação e Tecnologia Ambiental REGET/UFSM (e-ISSN: 2236-1170).}

\section{REVISÃO DE LITERATURA}

A Geografia, desde sua origem como campo do conhecimento e, mesmo antes, desde a Antiguidade, sempre se preocupou em compreender o espaço geográfico, ou o espaço "morada" do homem (e das mulheres) no planeta Terra.

Sobre geografia as idéias aqui expostas encontram-se SUERTEGARAY (2000, p.96):

Constitui, portanto, uma ciência cujo conceito balizador de seus estudos é o espaço geográfico. Entende-se por espaço geográfico a materialização das práticas humanas sobre a superfície da terra (no sentido amplo). Trata-se de refletir sobre a produção do espaço na sua relação complexa e contraditória entre as práticas humanas que decorrem de seu modelo de produzir, de sua forma de se organizar socialmente e da construção de sua cultura.

Pensando dessa forma, o espaço geográfico constitui uma totalidade impossível de ser contemplada analiticamente. Por essa razão, acredita-se que este possa ser lido a partir de diferentes conceitos, expressão diferenciada da leitura geográfica sobre os espaço geográfico. Entre esses conceitos, tem-se o conceito de ambiente, o conceito escolhido para a discussão neste momento. Mas não devemos esquecer, a título de exemplo, de outros como, domínio, paisagem, região, território, geossistemas, redes, lugar.

Cada conceito permite uma leitura diferenciada e complementar daquilo que conceituamos como e espaço geográfico. Muitas dimensões do planeta/mundo sob diferentes óticas e escalas, expressam o conhecimento adquirido e refletem as respostas de vários campos disciplinares. Neste caso, estamos buscando expressar o olhar da Geografia.

Ambiente é um desses conceitos, ele nos permite avaliar, analisar uma dimensão do espaço geográfico. Trata-se de um conceito trabalhado em outros campos do conhecimento, desde a física (com a ideia de meio) à biologia (com a ideia de meio ambiente).

No caso das ciências ditas ecológicas, a tendência é pensar e analisar o ambiente como impactos naturais, transformações na natureza, tendo esta condição, na outra ponta da lógica, a atividade do homem, muitas vezes pensada de forma genérica, como processo exclusivamente biológico produzido por um ser devastador.

De acordo com PIRES (2000. p.19):

Efetivamente, um trabalho local pode conduzir a uma gestão territorial integrada ao ambiente se as tomadas e ações forem ao encontro das necessidades da população, levando os cidadãos a verem a ocorrência dos problemas ambientais nos lugares em que vivem. Para tanto, as comunidades envolvidas devem ser agentes dessa ação. É necessário promover, rapidamente, a recuperação sócio-espacial de lugares degradados através do resgate da participação social e da busca de identidades locais, possibilitando, assim, uma valorização ambiental.

Pensar o ambiente em Geografia é considerar a relação natureza/sociedade, uma conjunção complexa e conflituosa, que resulta do longo processo de socialização da natureza pelo 


\title{
Revista Eletrônica em Gestão, Educação e Tecnologia Ambiental \\ REGET/UFSM (e-ISSN: 2236-1170).
}

homem. Processo este que, ao mesmo tempo em que transforma a natureza, transforma, também, a natureza humana.

De acordo com o autor, "o conceito de ambiente, assim como o de natureza, são construções históricas que permitem conhecer e agir, daí a necessidade de discussão conceitual e nova construção do saber". (LEFF, 2001, p.162).

A Geografia que se refaz a partir dos anos $90 \mathrm{~m}$ tem como objetivo fazer o aluno compreender o mundo, na medida em que se compreenda nele e, na medida em que se compreendendo torna-se sujeito, não só do processo de conhecimento, como de transformação desse mesmo mundo. Construindo sua prática como indivíduo ou como grupo.

Este processo vem sendo entendido por REGO (2000, p. 102):

\begin{abstract}
A construção de ambiências, ou seja, processo de conhecimento de si e dos lugares construídos interativamente, na perspectiva de ação transformadora, uma noção de espaço geográfico, como um sistema composto por relações sociais articuladas e relações físico-sociais, espaço condicionador da existência humana e que pode, este espaço ser eleito como objeto catalisador de ações transformadoras exatamente por esse motivo por ser condicionador da existência humana.
\end{abstract}

A educação ambiental como tantas outras áreas de conhecimento pode assumir, assim, "uma parte ativa de um processo intelectual, constantemente a serviço da comunicação do entendimento e das solução dos problemas" (VIGOTSKY, 1991, p.43).

Trata-se de um aprendizado social, baseado no diálogo e na interação em constante processo de recriação e reinterpretação de informações, conceitos e significados, que podem se originar do aprendizado em sala de aula ou da experiência pessoal do aluno. Assim a escola pode transformar-se no espaço em que o aluno terá condições de analisar a natureza em um contexto entrelaçado de práticas sociais, parte componente de uma realidade mais complexa.

O mais desafiador é evitar cair na simplificação de que a educação ambiental poderá superar uma relação pouco harmoniosa entre os indivíduos e o meio ambiente mediante práticas localizadas e pontuais, muitas vezes distantes da realidade social de cada aluno. "Cabe sempre enfatizar a historicidade da concepção de natureza, o que possibilita a construção de uma visão mais abrangente, como é o caso das questões ambientais" (CARVALHO, 2001, p. 59).

A educação ambiental como formação e exercício de cidadania refere-se a uma nova forma de encarar a relação do homem com a natureza, baseada em uma nova ética, que pressupõe outros valores morais e uma forma diferente de ver o mundo e os homens.

A educação ambiental deve ser vista como um processo de permanente aprendizagem que valoriza as diversas formas de conhecimento e forma cidadãos com consciência local e planetária. 


\section{Revista Eletrônica em Gestão, Educação e Tecnologia Ambiental \\ REGET/UFSM (e-ISSN: 2236-1170).}

\section{CARACTERIZAÇÃO E HISTÓRICO DA ESCOLA JOSÉ FERREIRA RAMOS}

A E.E.E.F. José Ferreira Ramos está localizada no município de Gaurama-RS, e possui atualmente 220 alunos.

A escola atende um público bastante diversificado, considerando-se as condições de renda familiar, possuindo tanto alunos de famílias com renda média, quanto alunos com renda familiar baixa e muito baixo. Muitos educandos são moradores de bairros próximos a escola, outros, moradores do interior do município, necessitando de transporte para se deslocar até o local.

Através do Decreto 5636, de 03 de julho de 1934, foi criado o Grupo Escolar em Barro, município de Erechim.

O Interventor federal no Estado do Rio Grande do Sul, usando de suas atribuições, que Ihe conferiam a Constituição, art.2으, no 25 e de conformidade com o Decreto 3898, de 04 de outubro de 1927, resolve instituir um Grupo Escolar no povoado de Barro, município de Erechim. Esta escola funcionou precariamente em uma casa de madeira, em frente a Praça Matriz.

A partir deste Decreto, iniciou-se a construção do prédio do Grupo Escolar, localizado na rua José Sponchiado, onde hoje funciona a Creche.

Lavrado em Ata, no dia 10 de maio de 1937, consta a inauguração solene do Grupo Escolar Dr. José Carlos da Fonseca Milano, era então Governador do Estado, o General José Antonio Flores da Cunha.

A escola teve como sua primeira diretora a Srta. Pepita Marina Frassetto, como consta na ata de inauguração.

Nos anos de 1937 e 1938 a escola funcionou somente com alunos de 2a e 3a séries e um total de 37 e 60 alunos respectivamente e lecionavam na escola duas professoras.

O Decreto Lei no 720, de 29 de dezembro de 1944 altera o nome do povoado de Barro para Guarama, ratificando posteriormente pa Gaurama, pondo fim a questões semânticas e gráficas. Por ocasião desta troca, a escola também substituiu o nome de Grupo Escolar de Barro para Grupo Escolar da Sede.

Encerrando o ano letivo de 1972, o Grupo Escolar da Sede transferiu suas atividades para o prédio do Ginásio Estadual, endereço que permanece até hoje, na rua Líbano Alves de Oliveira, número 97.

Através do Decreto $n^{\circ}$ 28091, de 21 de dezembro de 1978, fica reorganizado o Grupo Escolar da Sede, o qual passa a ser Escola Estadual José Ferreira Ramos - 1a a 4a Série. Desde então passamos a ter como Patrono o Sr. José Ferreira Ramos, pai do então prefeito municipal desta época, o Sr. Rui Joaquim Ramos, escolhido por ter dedicado sua vida a educação.

A portaria no 05546, de 14 de março de 1979, autoriza o funcionamento das Classes de Jardim, níveis A e B. Posteriormente, no ano de 1985, o nome da Escola passa a designar-se Escola Estadual de 10 Grau Incompleto José Ferreira Ramos.

No ano de 1986, é autorizado o funcionamento de uma Classe Especial para atendimento de alunos com Necessidades Especiais. Em 1993, constando-se a necessidade de acompanhamento, principalmente para os alunos que passaram pela Classe Especial, é encaminhado pedido junto à $15^{a}$ Delegacia de Educação para que fosse formada uma Sala de 


\section{Revista Eletrônica em Gestão, Educação e Tecnologia Ambiental REGET/UFSM (e-ISSN: 2236-1170).}

Recursos, a fim de dar apoio pedagógico individualizado e em horário oposto ao das classes comuns.

A Portaria no 00065, de 23 de fevereiro de 2001, reorganiza novamente a escola, que passa a designar-se então Escola Estadual de Ensino Fundamental José Ferreira Ramos.

Em 03 de julho de 2009, este Educandário completou 75 anos de existência. Neste período a escola foi se fortalecendo e marcando sua história.

É uma longa caminhada onde a escola surgiu e cresceu com a cidade, abrangendo todas as raças, culturas, religiões e ideologias dos gauramenses. Ela esteve presente e acompanhou o crescimento de várias gerações, sem nunca se desviar de sua mais singela função, educar, para ter amanhã adultos responsáveis, críticos, criativos e com espírito humanístico.

\section{METODOLOGIA}

Visando fortalecer a identidade e valorizar o lugar, aumentando a auto-estima dos educandos é que foi criado o projeto de Educação Ambiental na escola. Com todas as carências e dificuldades enfrentadas para a operacionalização deste, foi possível criar novas ações para a valorização do espaço vivido e experimentar novas práticas.

Entretanto, era necessário fortalecer as ações buscando parcerias e desenvolvendo projetos alternativos que quebrem a rotina da instituição escolar, valorizando a criação de novas práticas que vão além do espaço escolar. Foi assim que, as atividades de educação ambiental, realizadas na escola, auxiliaram no desenvolvimento afetivo e cognitivo dos alunos proporcionando mudanças na relação com o espaço vivido cotidianamente.

Observou-se que o simples fato de ocorrerem atividades integrando professores e alunos da escola, estimulava as relações, demonstrando de forma concreta a viabilidade da transformação das práticas pedagógicas tradicionais, ainda que de forma lenta e gradual. O prazer da descoberta de novas possibilidades e do potencial da escola se refletiu, também, nas relações de convivência entre os professores que participavam do projeto e os alunos, gerando uma melhoria do ambiente de trabalho em sala de aula, em especial nas aulas de História e Geografia, nas turmas que possuíam alunos que participavam do grupo da Educação Ambiental.

Algumas atividades de educação ambiental merecem ser destacadas. Estas, partindo da observação dos impactos ambientais decorrentes da urbanização, proporcionaram novas leituras do espaço vivido pelos educandos, aproximando a escola do conhecimento produzido, proporcionando trocas enriquecedoras.

Vários processos degradacionais podem ser observados e o córrego transformou-se em objeto de pesquisa e recurso pedagógico para as aulas de Geografia. Os estudantes realizaram estudos sobre os impactos ambientais, ao mesmo tempo em que foram organizados trabalhos de reflexão e debates sobre a importância dos sistemas hídricos para a comunidade local.

Muitas sugestões surgiram ao compreenderem processos naturais e sociais que atuavam sobre o curso d'água estudado e os alunos ficaram estimulados ao trabalhar junto à comunidade, visando modificar posturas que contribuíam para a degradação ambiental.

Criou-se através da pesquisa, da observação dos alunos e das discussões em sala de aula, um ambiente bastante propício à reflexão sobre os valores e as condições que levavam as 


\section{Revista Eletrônica em Gestão, Educação e Tecnologia Ambiental \\ REGET/UFSM (e-ISSN: 2236-1170).}

pessoas ocuparem as margens dos cursos d'água, a forma como o homem se apropria da natureza, os processos naturais e sociais que modificam o ambiente, as ações que podem provocar os impactos ambientais e as consequências que a degradação dos sistemas hídricos podem trazer para a comunidade local.

Os estudantes participaram ainda de atividades pedagógicas, realizando trabalhos de campo: visitaram o Atero Sanitário, participaram de discussões a respeito do destino dos resíduos sólidos e líquidos produzidos no município, assistiram palestras com técnicos da EMATER/RS e participaram de muitas outras atividades culturais previstas pelo projeto de Educação Ambiental.

Nos trabalhos de campo, foi observado a gênese de um sentimento de pertencimento a outros lugares, que muitas vezes são considerados externos, por não se constituírem como parte do cotidiano. Evidenciou-se ainda, o desenvolvimento de uma certa solidariedade, ou seja, a descoberta de que pertencemos a um conjunto de lugares e de pessoas.

\section{RESULTADOS E DISCUSSÕES}

No trabalho de pesquisa realizado na Escola Estadual José Ferreira Ramos, localizada no município de Gaurama/RS, nota-se uma grande preocupação com as questões ambientais não só por parte dos professores, mas de toda a comunidade escolar.

Os docentes defendem com unanimidade a importância de se trabalhar o meio ambiente desde as séries iniciais, sendo aprofundadas gradativamente, para que se construa uma consciência ambiental onde os educandos entendam que são parte do ambiente e responsáveis pelas suas atitudes e escolhas. E é através da escola onde surgem espaços para o debate e o conhecimento que serão repassados para suas famílias e que levarão para o resto de suas vidas.

No momento em que o aluno cuida do meio ambiente, ele terá resultados positivos que o beneficiará em uma melhor convivência neste planeta.

O gráfico no. 1 mostra os principais problemas e preocupações que devem ser abordados pela Educação Ambiental na Escola José Ferreira Ramos.

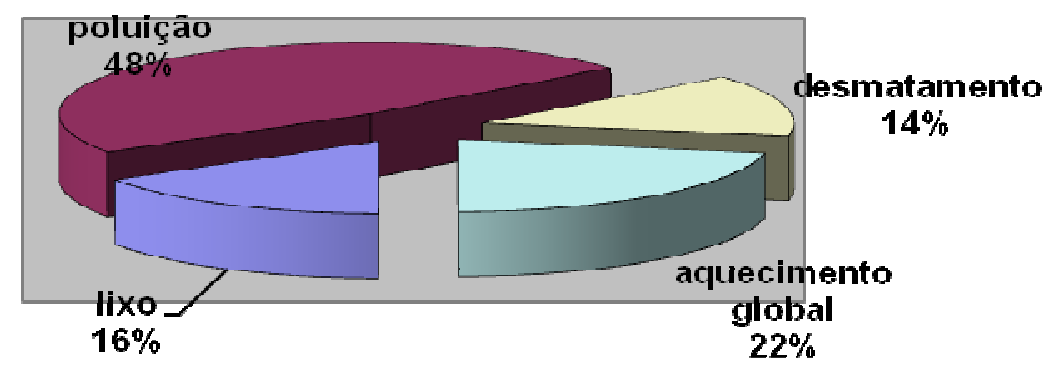




\section{Revista Eletrônica em Gestão, Educação e Tecnologia Ambiental \\ REGET/UFSM (e-ISSN: 2236-1170).}

A pesquisa de campo foi realizada através de um questionário com questões referentes ao trabalho de educação ambiental em sala de aula para os professores, alunos de 1a a 4a série do ensino fundamental e funcionários da escola em estudo.

Quando indagados sobre a melhor forma de se divulgar um programa de Educação Ambiental a maioria dos entrevistados afirmou que é por meio da televisão e do rádio por serem os meios de comunicação que as famílias tem mais acesso, assistem e ouvem com frequência.

Através desta entrevista se pode concluir que quando um projeto de educação ambiental é bem elaborado, o resultado, será sem dúvida, satisfatório e trará uma mudança de hábitos e atitudes permanentes.

\section{CONCLUSÃO}

A natureza fornece "recursos" e sustenta o desenvolvimento da sociedade, sendo pouco a pouco associada a ideia de habitat. Essa associação ajuda a entender o ambiente nas suas interações físicas e sociais, constituído por uma diversidade territorial de distintos indivíduos, grupos sociais e culturais. Por isso, os estudos ambientais tornam-se importante para o desenvolvimento das relações instauradas entre sociedade e natureza.

Muitos problemas ambientais, existentes no local, são resultantes da deficiência de infra-estrutura básica nos assentamentos urbanos, como esgoto sanitário, coleta de lixo e, sobretudo, a falta de controle e monitoramento ambiental por parte das comunidades envolvidas e órgãos governamentais. Esses processos intensificam a erosão e aumentam as áreas de deposição de sedimentos que atingem os leitos dos rios, gerando conflitos de uso do solo e deteriorando a qualidade das águas.

O diagnóstico desses conflitos servirá de base para problematizar o conhecimento e desenvolver habilidades e capacidades para se operar com o espaço geográfico. 0 projeto de educação ambiental é um instrumento que o professor pode utilizar para explicar e representar a construção de diferentes tipos de paisagens e territórios que compõe a geografia do lugar.

A educação ambiental visa auxiliar o aluno a agir no espaço e a influir na sua construção. Efetivamente possibilita: atitude de participação ativa na construção e produção de moradia; co-responsabilidade em gestão territorial; valorização da vida no espaço; respeito ao direito das pessoas pelo deslocamento espacial e ética ambiental. Como formação e exercício de cidadania refere-se a uma nova forma de encarar a relação do homem com a natureza, baseada numa nova ética, que pressupõe outros valores morais e uma forma diferente de ver o mundo e os homens.

Assim, justifica-se a importância da realização desse tipo de atividade, nas escolas voltadas para a educação popular. A solidariedade e o sentimento de pertencimento ao espaço global, despertado pelo contato com outros lugares e a possibilidade de novas leituras do espaço 


\section{Revista Eletrônica em Gestão, Educação e Tecnologia Ambiental REGET/UFSM (e-ISSN: 2236-1170).}

vivido a partir de experiências locais que são, na maioria das vezes, ignorados pelos conteúdos formais da escola tecnicista, devem estar presentes no ensino de Geografia, em todas escolas voltadas à construção da cidadania.

\section{REFERÊNCIAS}

CARVALHO, L. A invenção ecológica. Porto Alegre: Editora da UFRGS, 2001.

LEFF, H. Saber ambiental, Sustentabilidade, racionalidade, complexidade, poder. Petrópolis: vozes, 2001.

PIRES, Cláudia. Impactos ambientais decorrentes de ocupações clandestinas e irregulares junto às nascentes da bacia hidrográfica do Arroio do Salso. Porto Alegre: Editora da UFRGS, 2000.

REGO, N. Geografia e educação: geração de ambiências. Porto Alegre: Editora da UFRGS, 2000.

SURTEGARAY, D. M. A. Ambiente e lugar no urbano. Porto Alegre: Editora da UFRGS, 2000.

VIGOTSKY. A formação social da mente. São Paulo: Martins, 1991. 